\title{
Specialized Metabolites from Methylotrophic Proteobacteria
}

\author{
Aaron W. Puri* \\ Department of Chemistry and the Henry Eyring Center for Cell and Genome Science, University of Utah, Salt Lake \\ City, UT, USA.
}

*Correspondence: a.puri@utah.edu

https://doi.org/10.21775/cimb.033.211

\begin{abstract}
Biosynthesized small molecules known as specialized metabolites often have valuable applications in fields such as medicine and agriculture. Consequently, there is always a demand for novel specialized metabolites and an understanding of their bioactivity. Methylotrophs are an underexplored metabolic group of bacteria that have several growth features that make them enticing in terms of specialized metabolite discovery, characterization, and production from cheap feedstocks such as methanol and methane gas. This chapter will examine the predicted biosynthetic potential of these organisms and review some of the specialized metabolites they produce that have been characterized so far.
\end{abstract}

\section{Introduction}

Specialized metabolites, also known as secondary metabolites or natural products, form the basis of many bioactive compounds essential to modern medicine and agriculture (Demain and Sanchez, 2009; Cantrell et al., 2012; Newman and Cragg, 2016). This makes intuitive sense because production of these compounds is genetically encoded in biosynthetic gene clusters (BGCs) and therefore the resulting structures have had millennia to evolve their roles. The great value of these molecules in manipulating biological systems means there is a constant demand for new sources of these compounds and strategies for determining their biological functions.

The explosion in bacterial genome sequences available in public databases as well as the availability of bioinformatics tools for analysing them has revealed that many bacterial species are potentially untapped sources for new molecules (Cimermancic et al., 2014). This includes organisms beyond those traditionally relied upon for natural product discovery, and recent studies have shown that examining the biosynthetic potential of new species indeed reveals new classes of compounds (Pidot et al., 2014; Pye et al., 2017). This strategy is complementary to synthetic biology approaches focused on activating BGCs that are not normally expressed under laboratory conditions in strains traditionally used for natural product discovery, such as Streptomyces (Rutledge and Challis, 2015).

This chapter will focus on the methylotrophic Proteobacteria, which use reduced carbon compounds with no carbon-carbon bonds as their sole sources of carbon and energy. Specifically, the Proteobacteria are some of the most well-studied organisms within this metabolic group (Chistoserdova et al., 2009). While several molecules have been isolated from methylotrophic Proteobacteria that have had an impact on the field of natural products (Kenney and Rosenzweig, 2018a; Khmelenina et al., 2015), our understanding of the specialized metabolism of these organisms is still in its infancy. 


\section{Methylotrophic bacteria as an underexplored resource for specialized metabolite discovery}

Methylotrophic bacteria are an attractive source for the discovery of new specialized metabolites for several reasons.

1 Obligate methylotrophs, including many species of methane-oxidizing bacteria, may have been overlooked during traditional 'grind and find' searches for new compounds that focused on the isolation of specific genera like Streptomyces using rich media.

2 The lack of complex carbon substrate in methylotroph growth medium can aid in the rapid analysis of new compounds produced by a culture without laborious prefractionation procedures, which may also help in high throughput screening approaches.

3 The chemically defined nature of the growth medium and simplicity of the carbon source also allows substrates with heavy labels such as ${ }^{15} \mathrm{NO}_{3}$ and ${ }^{13} \mathrm{CH}_{4}$ or ${ }^{13} \mathrm{CH}_{3} \mathrm{OH}$ to be used for minimal cost, which can aid in structural elucidation using mass spectrometry and NMR.

4 If a molecule with attractive properties is identified, its methylotroph producer can be grown at scale using a feedstock such as methane or methanol, both of which have recently re-emerged as substrates of interest in industrial microbiology (Schrader et al., 2009; Henard and Guarnieri, 2018).

It is therefore worthwhile to discover more molecules produced by this ecologically important group of bacteria.

Genome sequencing efforts supported by entities including the Joint Genome Institute (JGI) and Organization for Methanotroph Genome Analysis (OMeGA) have enabled a detailed examination of the predicted biosynthetic potential of many methylotrophic species (Fig. 12.1). Amongst the strains analysed here, more BGCs are generally predicted in methanotroph genomes compared with the genomes of non-methanotrophic methylotrophs. Overall the Alphaproteobacteria, including members of the Methylobacterium genus among the non-methanotrophs, appear to possess a large number of predicted BGCs. The Methylobacterium genus was also highlighted for its substantial biosynthetic potential in a past analysis of bacterial genomes (Cimermancic et al., 2014). Many Alphaproteobacteria including methylotrophic species rely on the ethylmalonyl-CoA pathway to assimilate acetyl-CoA into central metabolism, and this pathway involves high flux through CoA-linked intermediates that are also often used in the synthesis of specialized metabolites such as polyketides (Alber, 2011). This makes the exploration of the specialized metabolism of these organisms particularly intriguing.

Bacteriocin and terpene BGCs were most commonly predicted within the categories classified by the antibiotic and secondary metabolite analysis shell (antiSMASH) (Blin et al., 2017). However, the majority of predicted clusters were detected using ClusterFinder, which relies on more probabilistic (and less stringent) methods for BGC identification (Cimermancic et al., 2014). This could suggest that methylotrophs produce different compounds than those made by traditionally studied organisms, which would be promising for the discovery of new classes of compounds. However, sequence homology-based comparisons to characterized BGCs and experimental verification will be essential to exploring the hypothesis that these gene clusters are producing novel products.

\section{Intercellular chemical communication}

\section{Quorum sensing}

Quorum sensing (QS) allows bacteria to control gene expression in a cell density-dependent manner. In Proteobacteria, a canonical QS signal is the acyl-homoserine lactone (acyl-HSL), which can vary in its acyl chain length, saturation, and oxidation. These signals are produced by LuxI-family acyl-HSL synthases, and detected by LuxR-family receptor/transcription factors. For reviews please see Papenfort and Bassler (2016) as well as Whiteley et al. (2017).

The first QS system to be characterized in a methylotroph was in the model strain Methylobacterium extorquens AM1 (Penalver et al., 2006). Researchers found that AM1 possesses two LuxI-family synthases, termed MlaI and MsaI. While MsaI produces the short chain acyl-HSLs $\mathrm{C}_{6}$ - and $\mathrm{C}_{8}-\mathrm{HSL}$, MlaI produces the more unusual unsaturated long 

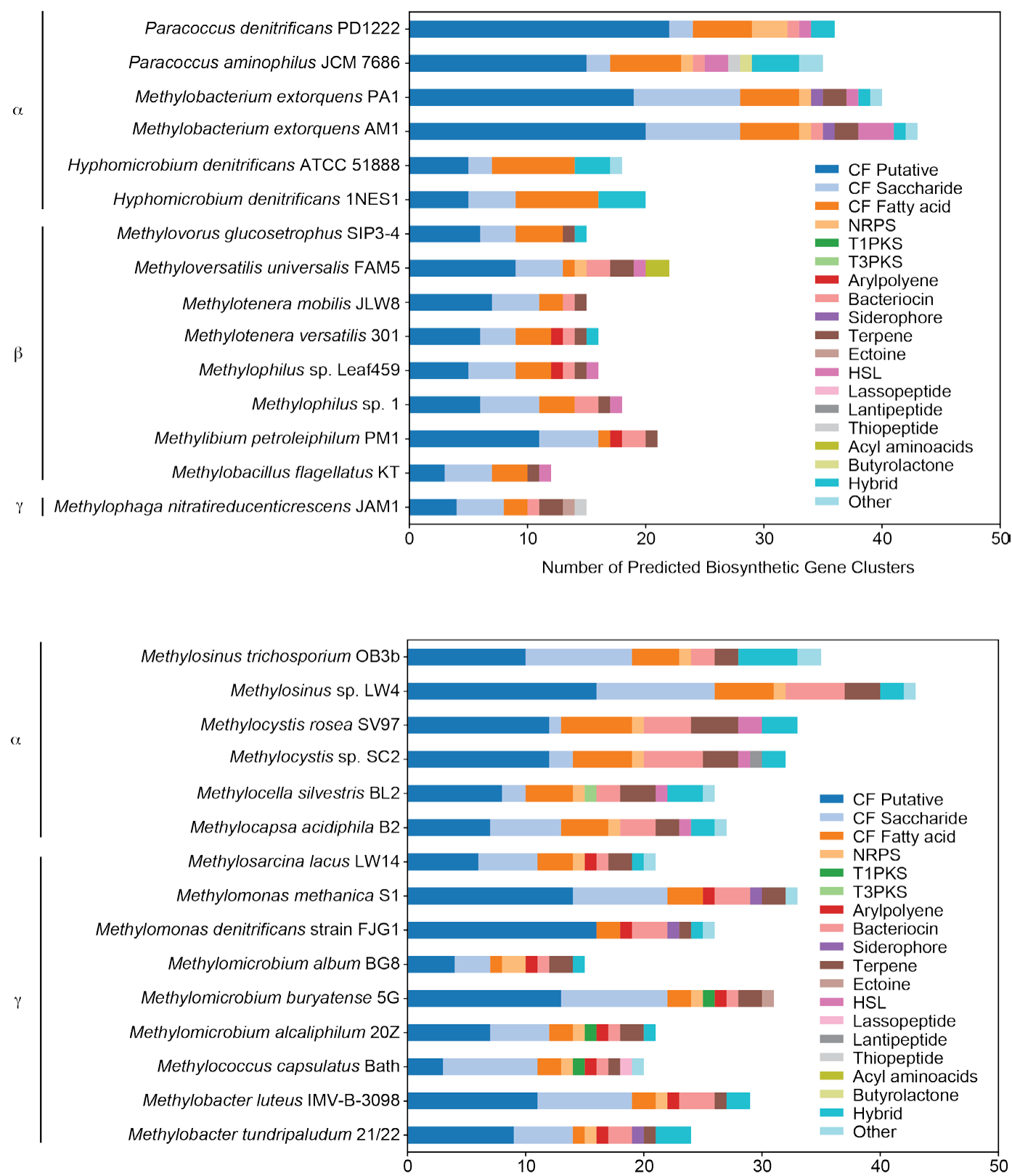

Number of Predicted Biosynthetic Gene Clusters

Figure 12.1 Predicted biosynthetic gene clusters in genomes of methylotrophic Proteobacteria. Predictions were made using antiSMASH 4.1.0 (Blin et al., 2017) with ClusterFinder (CF) (Cimermancic et al., 2014) enabled with default settings. HSL, homoserine lactone; NRPS, non-ribosomal peptide synthetase; PKS, polyketide synthase. 
chain molecules $7 Z-\mathrm{C}_{14}-\mathrm{HSL}$ and $2 E, 7 Z-\mathrm{C}_{14}-\mathrm{HSL}$ only when AM1 is grown on methanol (Table 12.1). The short chain acyl-HSLs produced by $M$. extorquens AM1 increase the production of exopolysaccharide (Penalver et al., 2006), and therefore could have a role in biofilm formation. In support of this, recently a highly homologous QS system in a Methylobacterium populi strain was found to regulate the structure and adherence of biofilms made by this organism (Morohoshi et al., 2018).

Many Methylobacterium species have been found to produce acyl-HSLs as detected by bioassays (Poonguzhali et al., 2007). In one study researchers found that the orange tree symbiont Methylobacterium mesophilicum SR 1.6/6 produces several signals, including novel variants (Table 12.1) (Pomini et al., 2009). There is some evidence that increased concentrations of these molecules may regulate the transcription of metabolic genes in this bacterium (Dourado et al., 2013), however the precise biological role of these QS signals will require further investigation.

A QS system was recently discovered and characterized in the methane-oxidizing Gammaproteobacterium Methylobacter tundripaludum $21 / 22$, which was isolated from lake sediment (Table 12.1) (Puri et al., 2017). This bacterium produces and responds to the signal $3-\mathrm{OH}-\mathrm{C}_{10}-\mathrm{HSL}$, which activates expression of a BGC co-located with the QS genes in M. tundripaludum. The same group of researchers subsequently identified the specialized metabolite product of this BGC, named tundrenone (see below) (Puri et al., 2018). The fact that tundrenone is produced in a QS-dependent manner fits the paradigm that QS systems often activate the production of extracellular factors such as antibiotics (McGowan et al., 1995; Duerkop et al., 2009) and proteases (Pearson et al., 1997), thereby allowing bacteria to affect their surrounding environment at high cell density.

It will be exciting to characterize more methylotroph QS systems in the future and determine their biological roles. It should be noted that methylotrophs occupy diverse ecological niches, including both acidic (Dedysh et al., 2000) and alkaline (Khmelenina et al., 1997) environments. The HSL ring is subject to base-catalysed hydrolysis (Schaefer et al., 2000; Dong et al., 2001), which may provide one explanation for why methylotrophs isolated from alkaline environments such as some Methylomicrobium species do not possess acyl-HSL-based quorum sensing systems in their genomes (Fig. 12.1).

\section{Interspecies chemical communication}

Specialized metabolites biosynthesized by methylotrophs have also been reported to be involved in interspecies interactions. The copper-binding small molecule methanobactin (see below) is produced by many methanotrophs, but its structure varies between species (Kenney and Rosenzweig, 2018a). It was reported that methanobactin produced by Methylocystis sp. str. SB2 may regulate the

Table 12.1 Acyl-homoserine lactone quorum sensing signals produced by methylotrophic Proteobacteria

\begin{tabular}{lll}
\hline Producing strain & Acyl-homoserine lactone signal & Reference \\
\hline Methylobacterium extorquens AM1 & $\mathrm{C}_{6}-\mathrm{HSL}$ & Penalver et al. (2006) \\
& $\mathrm{C}_{8}-\mathrm{HSL}$ & \\
& $7 \mathrm{Z}-\mathrm{C}_{14}-\mathrm{HSL}$ & \\
& $2 \mathrm{E}, 7 \mathrm{Z}-\mathrm{C}_{14}-\mathrm{HSL}$ & Pomini et al. (2009) \\
Methylobacterium mesophilicum SR 1.6/6 & $\mathrm{C}_{12}-\mathrm{HSL}$ & \\
& $\mathrm{C}_{13}-\mathrm{HSL}$ & \\
& $\mathrm{C}_{14}-\mathrm{HSL}$ & \\
& $2 \mathrm{E}-\mathrm{C}_{12}-\mathrm{HSL}$ & \\
& $7 \mathrm{Z}-\mathrm{C}_{14}-\mathrm{HSL}$ & Puri et al. (2017) \\
& $2 \mathrm{E}, 7 \mathrm{Z}-\mathrm{C}_{14}-\mathrm{HSL}$ & Morohoshi et al. (2018) \\
Methylobacter tundripaludum 21/22 & $3-\mathrm{OH}-\mathrm{C}_{10}-\mathrm{HSL}$ & \\
\hline
\end{tabular}

Note: While the full stereochemistry has not been determined for all molecules, all biologically produced acylhomoserine lactone (acyl-HSL) signals where stereochemistry has been determined possess an (S)- $N$ - configuration. aStereochemistry of unsaturated bond not determined. 
expression of genes related to methane oxidation in Methylosinus trichosporium OB3b via mechanisms beyond simply altering copper availability (Farhan Ul-Haque et al., 2015). The ability of methanotrophs to interact with methanobactin produced by other species points to piracy between these organisms and suggests a fierce competition for copper in the environment (El Ghazouani et al., 2012; Dassama et al., 2016; DiSpirito et al., 2016).

The presence of volatile specialized metabolites in interactions between methanotrophs and nonmethylotrophicheterotrophs has also been surveyed (Veraart et al., 2018). The methanotroph Methylobacter luteus was reported to produce the volatile bicyclic terpenoids cadinene and alpha-murolene in response to the presence of the heterotroph Pseudomonas mandelli. The role of these compounds in interactions between metabolically linked methanotrophs and non-methanotrophic species will require further investigation.

\section{Examples of molecules produced by methylotrophs}

\section{Methanobactin}

The particulate methane monooxygenase (pMMO) is found in almost all methane-oxidizing bacteria, and it requires copper to catalyse the oxidation of methane to methanol (Balasubramanian et al., 2010). Consequently, methanotrophs have a great need for copper and use specialized mechanisms for its acquisition (Semrau et al., 2010; Kenney and Rosenzweig, 2018b). Several methanotrophs that are members of the Alphaproteobacteria secrete a ribosomally produced and post-translationally modified peptide (RiPP) that tightly binds copper termed methanobactin (Table 12.2) (Kim et al., 2004). Because of its relation to iron binding siderophores, methanobactin is known as a chalkophore. Methanobactin is perhaps the most well known of all characterized specialized metabolites produced by methylotrophs. For more comprehensive reviews of methanobactin please see DiSpirito et al. (2016) as well as Kenney and Rosenzweig (2018a).

Although the exact structure of methanobactin varies between species, all isolated versions coordinate copper using oxazolone rings or heterocycles with similar functionality and neighbouring enethiol/thioamide groups (Kenney and Rosenzweig, 2018a). The formation of the oxazole ring and thioamide in methanobactin was recently characterized, and involves the protein complex MbnBC, which contains domains of previously unrecognized function (Kenney et al., 2018). Understanding the molecular mechanisms of methanobactin biosynthesis may ultimately enable the production of methanobactin analogues with varying properties.

Applications of methanobactin include its use as a chelation therapy for copper toxicity such as in Wilson disease (Lichtmannegger et al., 2016). Methanobactin from $M$. trichosporium OB3b also binds other metals including gold with high affinity (Choi et al., 2006), making it useful for biomining as well as nanoparticle preparations (DiSpirito et al., 2016). This versatile compound also has growth inhibitory activity against a range of bacteria (DiSpirito et al., 2007), which is a less discussed property of methanobactin but which may play a role in shaping the composition of methane-oxidizing bacterial communities in nature. Methanobactin production is activated by low copper availability, making it similar to other specialized metabolites that have tightly regulated production (Kim et al., 2004; Kenney et al., 2016; Gu and Semrau, 2017). Genome mining has also identified methanobactin BGCs in other non-methyltrophic species (Kenney and Rosenzweig, 2013), and it will be interesting to see what role methanobactins play in these bacteria.

\section{Toblerols}

Modular, non-iterative polyketide synthases (PKSs) follow an assembly line logic that often makes it possible to predict the structure of the metabolite product (Till and Race, 2016). The products of trans-acyltransferase (trans-AT) PKSs can be more difficult to predict, however detailed studies of the genes in these BGCs has resulted in a set of product prediction rules for these modular synthases as well (Nguyen et al., 2008). Recently, researchers investigated an unusual trans-AT PKS gene cluster in M. extorquens AM1 that could not be classified using previously developed approaches (Ueoka et al., 2017). The products of the cluster were found to be a family of novel molecules containing cyclopropanol moieties, and these compounds were subsequently named the toblerols (Table 12.2). The authors discovered that toblerol $\mathrm{C}$ suppresses the production of an additional factor 


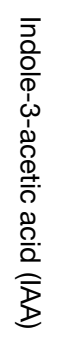

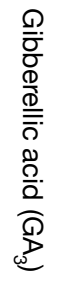
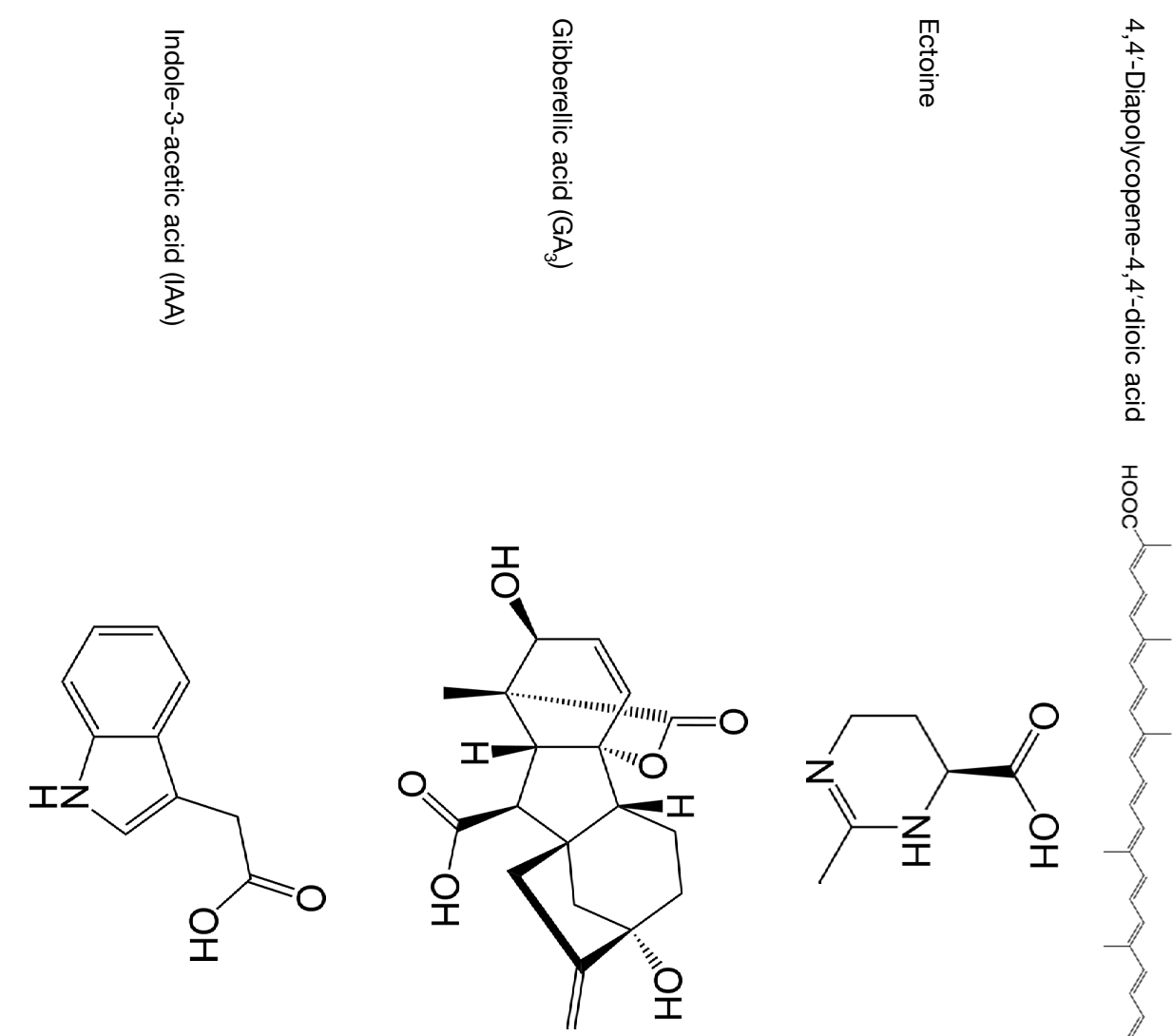

동

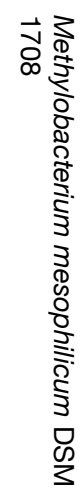

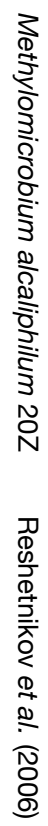

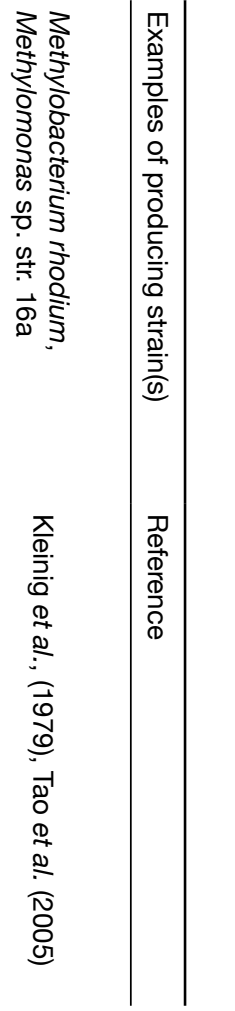




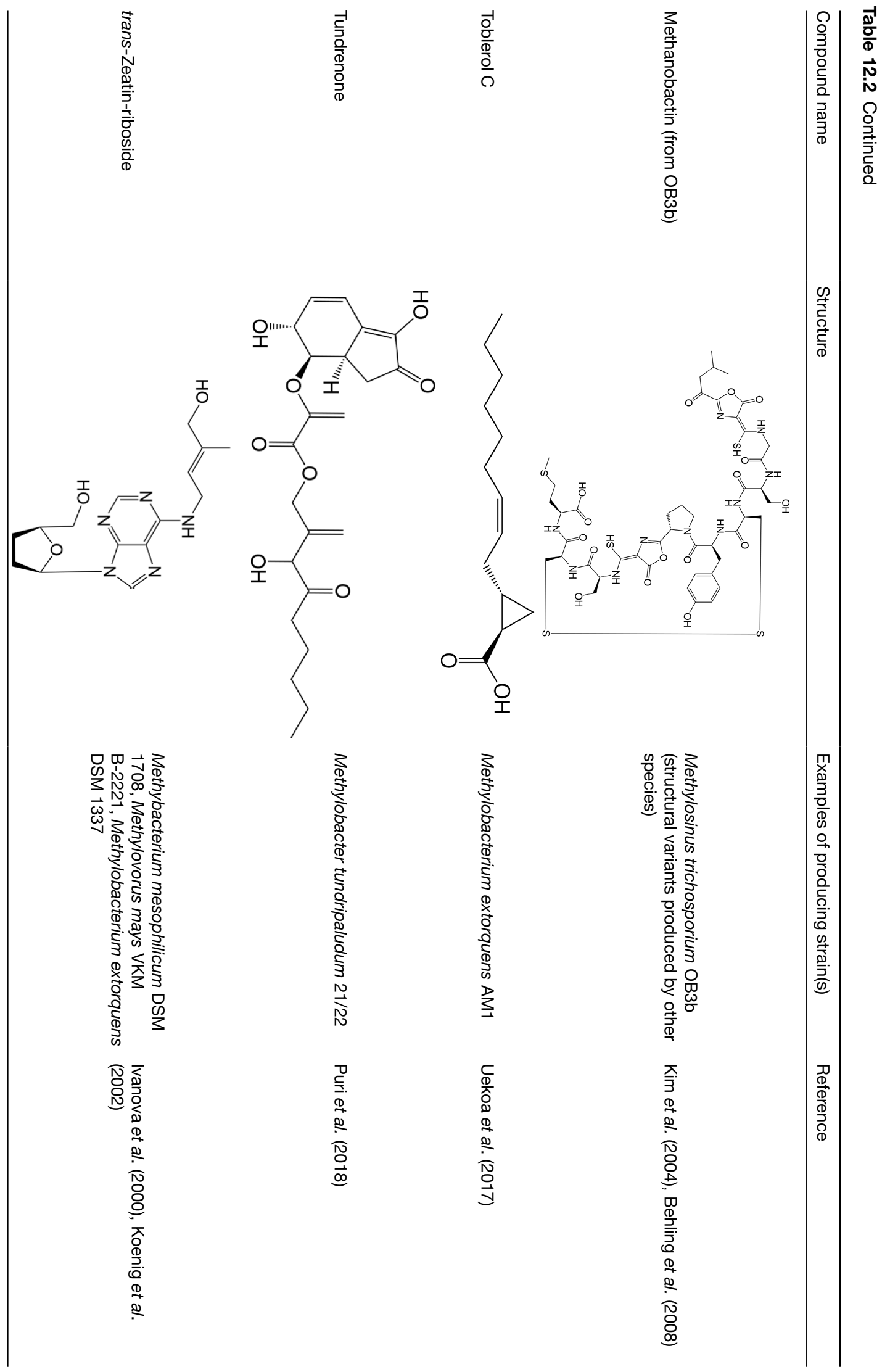


that inhibits the growth of other Methylobacterium isolates. The actual factor that causes growth inhibition is currently under investigation, but the results so far point to an intriguing hierarchy of bioactive small molecule production and regulation in these bacteria. This study highlights an example where a methylotroph contains a non-canonical BGC that produces novel specialized metabolites, demonstrating the utility of methylotrophs as an underexplored source of these molecules.

\section{Tundrenone}

Tundrenone is a novel specialized metabolite produced by the methanotroph $M$. tundripaludum in a quorum sensing-dependent manner (Puri et al., 2017, 2018). Tundrenone contains a tetrahydroindenone core predicted to be derived from the primary metabolite chorismate, as well as a lipid tail with unusual modifications (Table 12.2). These notable structural features suggest that an understanding of tundrenone's biosynthesis may uncover new enzymatic reactions that are useful for understanding and engineering the biosynthesis of other small molecules. The biological function of tundrenone is currently unknown, however the BGC responsible for tundrenone production is conserved in M. tundripaludum isolates from across the globe (Puri et al., 2017), suggesting that this molecule may have an ecologically significant role for this organism.

\section{Carotenoids}

Many methylotrophs are pigmented, as the responsible carotenoids can provide antioxidant effects including protecting their hosts from UV damage (Birben et al., 2012; Vorholt, 2012). This fact also has led to the commonly used descriptive grouping of pink pigmented facultative methylotrophs (PPFMs), which includes many species of the Methylobacterium genus that are found in association with plants (see below). Methylobacterium rhodium (formerly Pseudomonas rhodos) produces $\mathrm{C}_{30}$-carotenoids including 4,4'-diapolycopene-4,4'dioic acid diesters that contain conjugated sugars (Table 12.2) (Kleinig et al., 1979). These unusual molecules are not known to be produced by many bacterial species, but they were also found to be produced by methane-oxidizing bacteria of the genus Methylomonas (Tao et al., 2005). An oxidase in strain $16 \mathrm{a}$ termed $\mathrm{CrtNb}$ has been identified and characterized that functionalizes the termini of the precursor molecule 4,4'-diapolycopene with aldehyde moieties (Tao et al., 2005). This enzyme may be useful for future modification strategies for these pigments to be employed in semisynthetic processes.

Production of the more traditional $\mathrm{C}_{40}$ carotenoids has also been studied in methylotrophs. Methylobacterium species are known to produce $\mathrm{C}_{40}$ carotenoids such as oscillaxanthin (Van Dien et al., 2003; Konovalova et al., 2007). Additionally, Methylomonas sp. str. 16a has been used as a chassis for the production of the $\mathrm{C}_{40}$ carotenoid astaxanthin (Ye et al., 2007). An astaxanthin-producing methanotroph could be used in aquaculture as a single cell protein source that simultaneously enhances the pigmentation of the farmed animals.

\section{Ectoine}

Ectoine is a cyclic imino acid that functions as an osmoprotectant in many species of halotolerant and halophilic bacteria, including several methylotrophic species found in ecosystems with high salinity (Table 12.2) (Galinski et al., 1985; Reshetnikov et al., 2011). The biosynthesis of ectoine has been studied in the halotolerant methane-oxidizing bacterium Methylomicrobium alcaliphilum $20 \mathrm{Z}$ (Reshetnikov et al., 2005, 2006), which was isolated from a soda lake in Russia (Khmelenina et al., 1997; Kalyuzhnaya et al., 2008). Ectoine is produced from aspartic acid by the products of the ect $A B C$ biosynthetic gene cluster, and its production markedly increases under osmotic stress (Reshetnikov et al., 2011). As with many specialized metabolites, the biosynthesis of ectoine is transcriptionally regulated. The ectABC BGC also contains a co-located MarRtype transcriptional repressor, which is partially responsible for regulation of ect $A B C$ expression at different salt concentrations (Mustakhimov et al., 2010). Production of ectoine is of commercial interest because this compatible solute is valuable for the preservation of biologics including those used in cosmetics and medicine, and currently ectoine is produced biosynthetically for commercial means (Graf et al., 2008; Kunte et al., 2014). Consequently there is interest in production of this specialized metabolite from methane gas, a cheap and abundant feedstock for industrial biotechnology. 


\section{Phytohormones}

Plant stomata release methanol during growth as a by-product of pectin demethylation (NemecekMarshall et al., 1995; Galbally and Kirstine, 2002), and this methanol is in turn catabolized by resident methylotrophs that occupy the phyllosphere (Vorholt, 2012). In addition to this metabolic link, the relationship between plants and methylotrophs is thought to be mutualistic, with methylotrophs providing phytohormones to their plant hosts (Holland et al., 2002; Kutschera, 2007; Fedorov et al., 2011).

In support of the close link between plants and methylotrophs, Methylobacterium species have been found to promote the growth of plants, and the molecular details of these interactions have been investigated. For example, strains of M. mesophilicum and Methylovorus mays were found to produce substances that promote the growth of Amarantus caudatus seedlings, including the cytokinin zeatin (Ivanova et al., 2000). trans-Zeatin biosynthesis in Methylobacterium spp. was later found to involve tRNA precursors (Koenig et al., 2002); however, removal of trans-zeatin alone from bacterial cultures had no effect on soybean seed germination stimulation.

Methylotrophs have also been reported to synthesize additional phytohormones, including auxins and gibberellins. Researchers found that $M$. mesophilicum and Aminobacter aminovorans strains produce the canonical auxin indole-3-acetic acid (IAA) (Ivanova et al., 2001), which exerts major influences on plant growth and development (Duca et al., 2014). Furthermore, a Methylobacterium oryzae strain (Siddikee et al., 2010) as well as the obligate methylotroph Methylobacillus arboreus (Agafonova et al., 2018) have been reported to produce bioactive gibberellic acid $\mathrm{GA}_{3}$, and $\mathrm{GA}_{3}$ from the latter strain stimulated the sprouting of lettuce seeds.

These molecules point to a complex chemical conversation between methylotrophs and their plant hosts, as plants are canonical producers of natural products.

\section{Conclusions}

The specialized metabolites that have been isolated and characterized to date from methylotrophic
Proteobacteria have led to the discovery of novel structures, molecular functions, and enzymatic transformations. These efforts also underscore the continued utility of isolating bacterial strains and characterizing the compounds they produce naturally. While culturing these organisms may involve specialized knowledge or equipment, doing so can aid in the discovery of a metabolite's biological activity due to biological context. Isolating naturally produced compounds can also add some certainty that a molecule of interest is the actual product of the native pathway, which can be an issue for discovery efforts based on heterologous expression. The predicted biosynthetic potential of methylotrophic Proteobacteria, along with several practical advantages based on the growth conditions of these bacteria, make this an exciting time to investigate the specialized metabolism of these organisms.

\section{Future directions}

It has become increasingly clear that many bacterial BGCs are not expressed in axenic cultures grown under laboratory conditions (Milshteyn et al., 2014; Rutledge and Challis, 2015). Consequently, biological context is necessary for both the production of many specialized metabolites and an understanding of their bioactivity. Methylotrophic bacteria occupy a diversity of niches, and one particularly intriguing future direction for the study of specialized metabolites produced by these organisms is in the context of microbe-microbe and microbe-host interactions. Examples include plant-microbe interactions, where recently a Methylophilus strain was found to produce factor(s) that inhibit the growth of several other phyllosphere constituents (Helfrich et al., 2018). Methylotrophs are also symbionts of marine animals (Cavanaugh et al., 1987; Petersen and Dubilier, 2009), and a sponge symbiont with a large biosynthetic repertoire was recently predicted to have the ability to catabolize methanol (Lackner et al., 2017). Finally, the metabolic relationships between methane-oxidizing bacteria and the non-methanotrophic heterotrophs they support in the environment may provide context for the discovery of new molecules (Oshkin et al., 2014; Krause et al., 2017; Veraart et al., 2018). It will be exciting to see the developments in each of these areas in the years to come. 


\section{Web resources}

- Antibiotics and secondary metabolite analysis shell (antiSMASH): https://antismash.secondarymetabolites.org/

- MIBiG Repository: https://mibig.secondarymetabolites.org/repository.html

- JGI Integrated Microbial Genomes and Microbiomes: https://img.jgi.doe.gov/

- Carotenoids Database: http://carotenoiddb.jp/

\section{Acknowledgements}

A.W.P. was supported by the National Institute of General Medical Sciences of the National Institutes of Health under award number K99GM118762. The content is solely the responsibility of the author and does not necessarily represent the official views of the National Institutes of Health.

\section{References}

Agafonova, N.V., Kaparullina, E.N., Doronina, N.V., and Trotsenko, Y.A. (2018). Obligate methylotroph Methylobacillus arboreus IvaT synthesizes a plant hormone, gibberellic acid GA3. Microbiology 87, 47-50 https://doi.org/10.1134/S0026261718010022.

Alber, B.E. (2011). Biotechnological potential of the ethylmalonyl-CoA pathway. Appl. Microbiol. Biotechnol. 89, 17-25. https://doi.org/10.1007/ s00253-010-2873-z

Balasubramanian, R., Smith, S.M., Rawat, S., Yatsunyk, L.A., Stemmler, T.L., and Rosenzweig, A.C. (2010). Oxidation of methane by a biological dicopper centre. Nature 465, 115-119. https://doi.org/10.1038/nature08992

Birben, E., Sahiner, U.M., Sackesen, C., Erzurum, S., and Kalayci, O. (2012). Oxidative stress and antioxidant defense. World Allergy Organ. J. 5, 9-19 https://doi. org/10.1097/WOX.0b013e3182439613

Blin, K., Wolf, T., Chevrette, M.G., Lu, X., Schwalen, C.J., Kautsar, S.A., Suarez Duran, H.G., de Los Santos, E.L.C., Kim, H.U., Nave, M., et al. (2017). antiSMASH 4.0-improvements in chemistry prediction and gene cluster boundary identification. Nucleic Acids Res. 45, W36-W41. https://doi.org/10.1093/nar/gkx319

Behling, L.A., Hartsel, S.C., Lewis, D.E., DiSpirito, A.A., Choi, D.W., Masterson, L.R., Veglia, G., and Gallagher, W.H. (2008). NMR, mass spectrometry and chemical evidence reveal a different chemical structure for methanobactin that contains oxazolone rings. J. Am. Chem. Soc. 130, 12604-12605. https://doi. org/10.1021/ja804747d

Cantrell, C.L., Dayan, F.E., and Duke, S.O. (2012). Natural products as sources for new pesticides. J. Nat. Prod. 75, 1231-1242. https://doi.org/10.1021/np300024u

Cavanaugh, C.M., Levering, P.R., Maki, J.S., Mitchell, R., and Lidstrom, M.E. (1987). Symbiosis of methylotrophic bacteria and deep-sea mussels. Nature 325, 346-348. https://doi.org/10.1038/325346a0
Chistoserdova, L., Kalyuzhnaya, M.G., and Lidstrom, M.E. (2009). The expanding world of methylotrophic metabolism.Annu. Rev. Microbiol.63,477-499.https:// doi.org/10.1146/annurev.micro.091208.073600

Choi, D.W., Do, Y.S., Zea, C.J., McEllistrem, M.T., Lee, S.W., Semrau, J.D., Pohl, N.L., Kisting, C.J., Scardino, L.L., Hartsel, S.C., et al. (2006). Spectral and thermodynamic properties of $\mathrm{Ag}(\mathrm{I}), \mathrm{Au}(\mathrm{III}), \mathrm{Cd}(\mathrm{II})$, $\mathrm{Co}(\mathrm{II}), \mathrm{Fe}(\mathrm{III}), \mathrm{Hg}(\mathrm{II}), \mathrm{Mn}(\mathrm{II}), \mathrm{Ni}(\mathrm{II}), \mathrm{Pb}(\mathrm{II}), \mathrm{U}(\mathrm{IV})$, and $\mathrm{Zn}$ (II) binding by methanobactin from Methylosinus trichosporium OB3b. J. Inorg. Biochem. 100, 2150-2161.

Cimermancic, P., Medema, M.H., Claesen, J., Kurita, K., Wieland Brown, L.C., Mavrommatis, K., Pati, A., Godfrey, P.A., Koehrsen, M., Clardy, J., et al. (2014). Insights into secondary metabolism from a global analysis of prokaryotic biosynthetic gene clusters. Cell $158,412-421$.

Dassama, L.M., Kenney, G.E., Ro, S.Y., Zielazinski, E.L., and Rosenzweig, A.C. (2016). Methanobactin transport machinery. Proc. Natl. Acad. Sci. U.S.A. 113, 1302713032.

Dedysh, S.N., Liesack, W., Khmelenina, V.N., Suzina, N.E., Trotsenko, Y.A., Semrau, J.D., Bares, A.M., Panikov, N.S., and Tiedje, J.M. (2000). Methylocella palustris gen. nov., sp. nov., a new methane-oxidizing acidophilic bacterium from peat bogs, representing a novel subtype of serinepathway methanotrophs. Int. J. Syst. Evol. Microbiol. 50, 955-969. https://doi.org/10.1099/00207713-503-955

Demain, A.L., and Sanchez, S. (2009). Microbial drug discovery: 80 years of progress. J. Antibiot. 62, 5-16. https://doi.org/10.1038/ja.2008.16

DiSpirito, A., Zahn, J., Graham, D., Kim, H., Alterman, M., and Larive, C. (2007). Methanobactin: a copper binding compound having antibiotic and antioxidant activity isolated from methanotrophic bacteria. US7199099B2.

DiSpirito, A.A., Semrau, J.D., Murrell, J.C., Gallagher, W.H., Dennison, C., and Vuilleumier, S. (2016). Methanobactin and the Link between Copper and Bacterial Methane Oxidation. Microbiol. Mol. Biol. Rev. 80, 387-409. https://doi.org/10.1128/MMBR.0005815

Dong, Y.H., Wang, L.H., Xu, J.L., Zhang, H.B., Zhang, X.F., and Zhang, L.H. (2001). Quenching quorumsensing-dependent bacterial infection by an $N$-acyl homoserine lactonase. Nature 411, 813-817. https:// doi.org/10.1038/35081101

Dourado, M.N., Bogas, A.C., Pomini, A.M., Andreote, F.D., Quecine, M.C., Marsaioli, A.J., and Araújo, W.L. (2013). Methylobacterium-plant interaction genes regulated by plant exudate and quorum sensing molecules. Braz. J. Microbiol. 44, 1331-1339.

Duca, D., Lorv, J., Patten, C.L., Rose, D., and Glick, B.R. (2014). Indole-3-acetic acid in plant-microbe interactions. Antonie Van Leeuwenhoek 106, 85-125. https://doi.org/10.1007/s10482-013-0095-y

Duerkop, B.A., Varga, J., Chandler, J.R., Peterson, S.B., Herman, J.P., Churchill, M.E., Parsek, M.R., Nierman, W.C., and Greenberg, E.P. (2009). Quorum-sensing control of antibiotic synthesis in Burkholderia thailandensis. J. Bacteriol. 191, 3909-3918. https://doi. org/10.1128/JB.00200-09 
El Ghazouani, A., Baslé, A., Gray, J., Graham, D.W., Firbank, S.J., and Dennison, C. (2012). Variations in methanobactin structure influences copper utilization by methane-oxidizing bacteria. Proc. Natl. Acad. Sci. U.S.A. 109, 8400-8404. https://doi.org/10.1073/ pnas.1112921109

Farhan Ul-Haque, M., Kalidass, B., Vorobev, A., Baral, B.S., DiSpirito, A.A., and Semrau, J.D. (2015). Methanobactin from Methylocystis sp. strain SB2 affects gene expression and methane monooxygenase activity in Methylosinus trichosporium OB3b. Appl. Environ. Microbiol. 81, 2466-2473. https://doi.org/10.1128/AEM.03981-14

Fedorov, D.N., Doronina, N.V., and Trotsenko, I.u.A. (2011). Phytosymbiosis of aerobic methylobacteria: New facts and views. Mikrobiologiia 80, 435-446.

Galbally, I.E., and Kirstine, W. (2002). The production of methanol by flowering plants and the global cycle of methanol. J. Atmospheric Chem. 43, 195-229 https:// doi.org/10.1023/A:1020684815474

Galinski, E.A., Pfeiffer, H.P., and Trüper, H.G. (1985). 1,4,5,6-Tetrahydro-2-methyl-4-pyrimidinecarboxylic acid. A novel cyclic amino acid from halophilic phototrophic bacteria of the genus Ectothiorhodospira. Eur. J. Biochem. 149, 135-139.

Graf, R., Anzali, S., Buenger, J., Pfluecker, F., and Driller, H. (2008). The multifunctional role of ectoine as a natural cell protectant. Clin. Dermatol. 26, 326-333. https:// doi.org/10.1016/j.clindermatol.2008.01.002

Gu, W., and Semrau, J.D. (2017). Copper and ceriumregulated gene expression in Methylosinus trichosporium OB3b. Appl. Microbiol. Biotechnol. 101, 8499-8516. https://doi.org/10.1007/s00253-017-8572-2

Helfrich, E.J.N., Vogel, C.M., Ueoka, R., Schäfer, M., Ryffel, F., Müller, D.B., Probst, S., Kreuzer, M., Piel, J., and Vorholt, J.A. (2018). Bipartite interactions, antibiotic production and biosynthetic potential of the Arabidopsis leaf microbiome. Nat. Microbiol. 3, 909-919. https:// doi.org/10.1038/s41564-018-0200-0

Henard, C.A., and Guarnieri, M.T. (2018). Metabolic engineering of methanotrophic bacteria for industrial biomanufacturing. In Methane Biocatalysis: Paving the Way to Sustainability, M.G. Kalyuzhnaya, and X.-H. Xing, eds. (Springer International Publishing, Cham), pp. 117-132 https://doi.org/10.1007/978-3-31974866-5 8 .

Holland, $\bar{M}$., Long, R., and Polacco, J. (2002). Methylobacterium spp.: Phylloplane bacteria involved in cross-talk with the plant host? In Phyllosphere Microbiology, S. Lindow, E. Hect-Poinar, and V. Elliott, eds. (APS Press, St. Paul), pp. 125-135.

Ivanova, E.G., Doronina, N.V., Shepeliakovskaia, A.O., Laman, A.G., Brovko, F.A., and Trotsenko, I.u.A. (2000). Facultative and obligate aerobic methylobacteria synthesize cytokinins. Mikrobiologiia 69, 764-769.

Ivanova, E.G., Doronina, N.V., and Trotsenko, I.u.A. (2001). Aerobic methylobacteria are capable of synthesizing auxins. Mikrobiologiia 70, 452-458.

Kalyuzhnaya, M.G., Khmelenina, V., Eshinimaev, B., Sorokin, D., Fuse, H., Lidstrom, M., and Trotsenko, Y. (2008). Classification of halo(alkali)philic and halo(alkali) tolerant methanotrophs provisionally assigned to the genera Methylomicrobium and Methylobacter and emended description of the genus Methylomicrobium.
Int. J. Syst. Evol. Microbiol. 58, 591-596 https://doi. org/10.1099/ijs.0.65317-0

Kenney, G.E., and Rosenzweig, A.C. (2013). Genome mining for methanobactins. BMC Biol. 11, 17. https:// doi.org/10.1186/1741-7007-11-17

Kenney, G.E., and Rosenzweig, A.C. (2018a). Methanobactins: Maintaining copper homeostasis in methanotrophs and beyond. J. Biol. Chem. 293, 46064615. https://doi.org/10.1074/jbc.TM117.000185

Kenney, G.E., and Rosenzweig,A.C. (2018b). Chalkophores. Annu. Rev. Biochem. 87, 645-676. https://doi. org/10.1146/annurev-biochem-062917-012300

Kenney, G.E., Sadek, M., and Rosenzweig, A.C. (2016). Copper-responsive gene expression in the methanotroph Methylosinus trichosporium OB3b. Metallomics 8, 931940. https://doi.org/10.1039/c5mt00289c

Kenney, G.E., Dassama, L.M.K., Pandelia, M.E., Gizzi, A.S., Martinie, R.J., Gao, P., DeHart, C.J., Schachner, L.F., Skinner, O.S., Ro, S.Y., et al. (2018). The biosynthesis of methanobactin. Science 359, 1411-1416. https://doi. org/10.1126/science.aap9437

Khmelenina, V.N., Kalyuzhnaya, M.G., Starostina, N.G., Suzina, N.E., and Trotsenko, Y.A. (1997). Isolation and characterization of halotolerant alkaliphilic methanotrophic bacteria from Tuva soda lakes. Curr. Microbiol. 35, 257-261 https://doi.org/10.1007/ s002849900249

Khmelenina, V.N., Rozova, N., But, C.Y., Mustakhimov, I.I., Reshetnikov, A.S., Beschastnyi, A.P., and Trotsenko, Y.A. (2015). Biosynthesis of secondary metabolites in methanotrophs: biochemical and genetic aspects (review). Prikl. Biokhim. Mikrobiol. 51, 140-150.

Kim, H.J., Graham, D.W., DiSpirito, A.A., Alterman, M.A., Galeva, N., Larive, C.K., Asunskis, D., and Sherwood, P.M. (2004). Methanobactin, a copper-acquisition compound from methane-oxidizing bacteria. Science 305, 1612-1615. https://doi.org/10.1126/ science. 1098322

Kleinig, H., Schmitt, R., Meister, W., Gerhard, E., and Thommen, H. (1979). New C30-carotenoic acid glucosyl esters from Pseudomonas rhodos. Z. Für Naturforschung C 34, 181-185. https://doi.org/ https://doi.org/10.1515/znc-1979-3-404

Koenig, R.L., Morris, R.O., and Polacco, J.C. (2002). tRNA is the source of low-level trans-zeatin production in Methylobacterium spp. J. Bacteriol. 184, 1832-1842.

Konovalova, H.M., Shylin, S.O., and Rokytko, P.V. (2007). Characteristics of carotinoids of methylotrophic bacteria of Methylobacterium genus. Mikrobiol. Z. 69, 35-41.

Krause, S.M., Johnson, T., Samadhi Karunaratne, Y., Fu, Y., Beck, D.A., Chistoserdova, L., and Lidstrom, M.E. (2017). Lanthanide-dependent cross-feeding of methane-derived carbon is linked by microbial community interactions. Proc. Natl. Acad. Sci. U.S.A. 114, 358-363. https://doi.org/10.1073/ pnas. 1619871114

Kunte, H., Lentzen, G., and Galinksi, E. (2014). Industrial production of the cell protectant ectoine: protection mechanisms, processes, and products. Curr. Biotechnol. $3,10-25$.

Kutschera, U. (2007). Plant-associated methylobacteria as co-evolved phytosymbionts: a hypothesis. Plant Signal. Behav. 2, 74-78. 
Lackner, G., Peters, E.E., Helfrich, E.J., and Piel, J. (2017). Insights into the lifestyle of uncultured bacterial natural product factories associated with marine sponges. Proc. Natl. Acad. Sci. U.S.A. 114, E347-E356. https://doi. org/10.1073/pnas.1616234114

Lichtmannegger, J., Leitzinger, C., Wimmer, R., Schmitt, S., Schulz, S., Kabiri, Y., Eberhagen, C., Rieder, T., Janik, D., Neff, F., et al. (2016). Methanobactin reverses acute liver failure in a rat model of Wilson disease. J. Clin. Invest. 126, 2721-2735. https://doi.org/10.1172/JCI85226

McGowan, S., Sebaihia, M., Jones, S., Yu, B., Bainton, N., Chan, P.F., Bycroft, B., Stewart, G.S., Williams, P., and Salmond, G.P. (1995). Carbapenem antibiotic production in Erwinia carotovora is regulated by CarR, a homologue of the LuxR transcriptional activator. Microbiology 141, 541-550. https://doi. org/10.1099/13500872-141-3-541

Milshteyn, A., Schneider, J.S., and Brady, S.F. (2014). Mining the metabiome: identifying novel natural products from microbial communities. Chem. Biol. 21, 1211-1223. https://doi.org/10.1016/j.chembiol.2014.08.006

Morohoshi, T., Xie, X., and Ikeda, T. (2018). $\mathrm{N}$-Acylhomoserine lactone-mediated quorum sensing regulates biofilm structure in Methylobacterium populi $\mathrm{P}-1 \mathrm{M}$, an isolate from a pink-pigmented household biofilm. Biosci. Biotechnol. Biochem. [Epub ahead of print]. https://doi.org/10.1080/09168451.2018.1518 701

Mustakhimov, I.I., Reshetnikov, A.S., Glukhov, A.S., Khmelenina, V.N., Kalyuzhnaya, M.G., and Trotsenko, Y.A. (2010). Identification and characterization of EctR1, a new transcriptional regulator of the ectoine biosynthesis genes in the halotolerant methanotroph Methylomicrobium alcaliphilum 20Z. J. Bacteriol. 192, 410-417. https://doi.org/10.1128/JB.00553-09

Nemecek-Marshall, M., MacDonald, R.C., Franzen, J.J., Wojciechowski, C.L., and Fall, R. (1995). Methanol Emission from Leaves (Enzymatic Detection of GasPhase Methanol and Relation of Methanol Fluxes to Stomatal Conductance and Leaf Development). Plant Physiol. 108, 1359-1368.

Newman, D.J., and Cragg, G.M. (2016). Natural Products as Sources of New Drugs from 1981 to 2014. J. Nat. Prod. 79, 629-661. https://doi.org/10.1021/acs. jnatprod.5b01055

Nguyen, T., Ishida, K., Jenke-Kodama, H., Dittmann, E., Gurgui, C., Hochmuth, T., Taudien, S., Platzer, M., Hertweck, C., and Piel, J. (2008). Exploiting the mosaic structure of trans-acyltransferase polyketide synthases for natural product discovery and pathway dissection. Nat. Biotechnol. 26, 225-233. https://doi. org/10.1038/nbt1379

Nieto Penalver, C.G., Morin, D., Cantet, F., Saurel, O., Milon, A., and Vorholt, J.A. (2006). Methylobacterium extorquens AM1 produces a novel type of acylhomoserine lactone with a double unsaturated side chain under methylotrophic growth conditions. FEBS Lett. 580, 561-567.

Oshkin, I.Y., Beck, D.A., Lamb, A.E., Tchesnokova, V., Benuska, G., McTaggart, T.L., Kalyuzhnaya, M.G., Dedysh, S.N., Lidstrom, M.E., and Chistoserdova, L. (2014). Methane-fed microbial microcosms show differential community dynamics and pinpoint taxa involved in communal response. ISME J. 9, 1119-1129. https://doi.org/10.1038/ismej.2014.203.

Papenfort, K., and Bassler, B.L. (2016). Quorum sensing signal-response systems in Gram-negative bacteria. Nat. Rev. Microbiol. 14, 576-588. https://doi.org/10.1038/ nrmicro.2016.89

Pearson, J.P., Pesci, E.C., and Iglewski, B.H. (1997). Roles of Pseudomonas aeruginosa las and rhl quorumsensing systems in control of elastase and rhamnolipid biosynthesis genes. J. Bacteriol. 179, 5756-5767.

Penalver, C.G., Cantet, F., Morin, D., Haras, D., and Vorholt, J.A. (2006). A plasmid-borne truncated luxI homolog controls quorum-sensing systems and extracellular carbohydrate production in Methylobacterium extorquens AM1. J. Bacteriol. 188, 7321-7324.

Petersen, J.M., and Dubilier, N. (2009). Methanotrophic symbioses in marine invertebrates. Environ. Microbiol. Rep. 1, 319-335. https://doi.org/10.1111/j.17582229.2009.00081.x

Pidot, S.J., Coyne, S., Kloss, F., and Hertweck, C. (2014). Antibiotics from neglected bacterial sources. Int. J. Med. Microbiol. 304, 14-22. https://doi.org/10.1016/j. ijmm.2013.08.011

Pomini, A.M., Cruz, P.L., Gai, C., Araújo, W.L., and Marsaioli, A.J. (2009). Long-chain acyl-homoserine lactones from Methylobacterium mesophilicum: synthesis and absolute configuration. J. Nat. Prod. 72, 2125-2129. https://doi.org/10.1021/np900043j

Poonguzhali, S., Madhaiyan, M., and Sa, T. (2007). Production of acyl-homoserine lactone quorum-sensing signals is wide-spread in gram-negative Methylobacterium. J. Microbiol. Biotechnol. 17, 226-233.

Puri, A.W., Schaefer, A.L., Fu, Y., Beck, D.A., Greenberg, E.P., and Lidstrom, M.E. (2017). Quorum sensing in a methane-oxidizing bacterium. J. Bacteriol. 199, e00773-16.

Puri, A.W., Mevers, E., Ramadhar, T.R., Petras, D., Liu, D., Piel, J., Dorrestein, P.C., Greenberg, E.P., Lidstrom, M.E., and Clardy, J. (2018). Tundrenone: an atypical secondary metabolite from bacteria with highly restricted primary metabolism. J. Am. Chem. Soc. 140, 2002-2006. https://doi.org/10.1021/jacs.7b12240

Pye, C.R., Bertin, M.J., Lokey, R.S., Gerwick, W.H., and Linington, R.G. (2017). Retrospective analysis of natural products provides insights for future discovery trends. Proc. Natl. Acad. Sci. U.S.A. 114, 5601-5606. https://doi.org/10.1073/pnas.1614680114

Reshetnikov, A.S., Mustakhimov, I.I., Khmelenina, V.N., and Trotsenko, Y.A. (2005). Cloning, purification, and characterization of diaminobutyrate acetyltransferase from the halotolerant methanotroph Methylomicrobium alcaliphilum 20Z. Biochemistry Mosc. 70, 878-883.

Reshetnikov, A.S., Khmelenina, V.N., and Trotsenko, Y.A. (2006). Characterization of the ectoine biosynthesis genes of haloalkalotolerant obligate methanotroph 'Methylomicrobium alcaliphilum 20Z'. Arch. Microbiol. 184, 286-297. https://doi.org/10.1007/s00203-0050042-z

Reshetnikov, A.S., Khmelenina, V.N., Mustakhimov, I.I., Kalyuzhnaya, M., Lidstrom, M., and Trotsenko, Y.A. (2011). Diversity and phylogeny of the ectoine biosynthesis genes in aerobic, moderately halophilic 
methylotrophic bacteria. Extremophiles 15, 653-663. https://doi.org/10.1007/s00792-011-0396-x

Rutledge, P.J., and Challis, G.L. (2015). Discovery of microbial natural products by activation of silent biosynthetic gene clusters. Nat. Rev. Microbiol. 13, 509-523. https://doi.org/10.1038/nrmicro3496

Schaefer, A.L., Hanzelka, B.L., Parsek, M.R., and Greenberg, E.P. (2000). Detection, purification, and structural elucidation of the acylhomoserine lactone inducer of Vibrio fischeri luminescence and other related molecules. Meth. Enzymol. 305, 288-301.

Schrader, J., Schilling, M., Holtmann, D., Sell, D., Filho, M.V., Marx, A., and Vorholt, J.A. (2009). Methanolbased industrial biotechnology: current status and future perspectives of methylotrophic bacteria. Trends Biotechnol. 27, 107-115. https://doi.org/10.1016/j. tibtech.2008.10.009

Semrau, J.D., DiSpirito, A.A., and Yoon, S. (2010). Methanotrophs and copper. FEMS Microbiol. Rev. 34, 496-531. https://doi.org/10.1111/j.15746976.2010.00212.x

Siddikee, M., Hamayun, M., Han, G., and Sa, T. (2010). Optimization of gibberellic acid production by Methylobacterium oryzae CBMB20. Korean Soc. Soil Sci. Fertil. 43, 522-527.

Tao, L., Schenzle, A., Odom, J.M., and Cheng, Q. (2005). Novel carotenoid oxidase involved in biosynthesis of 4,4'-diapolycopene dialdehyde. Appl. Environ. Microbiol. 71, 3294-3301.

Till, M., and Race, P.R. (2016). The assembly line enzymology of polyketide biosynthesis. Methods Mol.
Biol. 1401, 31-49. https://doi.org/10.1007/978-14939-3375-4 2

Ueoka, R., Bortfeld-Miller, M., Morinaka, B.I., Vorholt, J.A., and Piel, J. (2017). Toblerols, cyclopropanol-containing modulators of methylobacterial antibiosis generated by an unusual polyketide synthase. Angew. Chem. Int. Ed. 1-7 https://doi.org/10.1002/anie.201709056

Van Dien, S.J., Marx, C.J., O’Brien, B.N., and Lidstrom, M.E. (2003). Genetic characterization of the carotenoid biosynthetic pathway in Methylobacterium extorquens AM1 and isolation of a colorless mutant. Appl. Environ. Microbiol. 69, 7563-7566.

Veraart, A.J., Garbeva, P., van Beersum, F., Ho, A., Hordijk, C.A., Meima-Franke, M., Zweers, A.J., and Bodelier, P.L.E. (2018). Living apart together-bacterial volatiles influence methanotrophic growth and activity. ISME J. 12, 1163-1166. https://doi.org/10.1038/s41396-0180055-7

Vorholt, J.A. (2012). Microbial life in the phyllosphere. Nat. Rev. Microbiol. 10, 828-840. https://doi.org/10.1038/ nrmicro2910

Whiteley, M., Diggle, S.P., and Greenberg, E.P. (2017). Progress in and promise of bacterial quorum sensing research. Nature 551, 313-320. https://doi. org/10.1038/nature24624

Ye, R.W., Yao, H., Stead, K., Wang, T., Tao, L., Cheng, Q. Sharpe, P.L., Suh, W., Nagel, E., Arcilla, D., et al. (2007). Construction of the astaxanthin biosynthetic pathway in a methanotrophic bacterium Methylomonas sp. strain 16a. J. Ind. Microbiol. Biotechnol. 34, 289-299. https:// doi.org/10.1007/s10295-006-0197-x 